\title{
Diagnosing the imbalance of Glaciar Santa Rosa, Cordillera Raura, Peru
}

\author{
Alcides Ames \\ División de Glaciología de Electroperu, Huaraz, Ancash, Peru \\ Stefan Hastenrath \\ Department of Atmospheric and Oceanic Sciences, University of Wisconsin-Madison, 1225 West Dayton Street, Madison, \\ Wisconsin 53706-1490, U.S.A.
}

\begin{abstract}
For Glaciar Santa Rosa, in the Cordillera Raura, Peru, the extent and volume are determined for 1980 and 1961 from topographic mapping, and for two undated earlier stages LME and MAX from moraines. The regime of the glacier in terms of ice flow and mass balance is evaluated for the 1977-83 period. More than half of the water discharge from the glacier is not renewed by precipitation but supplied by the ice thinning. The rate of surface lowering of $2 \mathrm{ma}^{-1}$ liquid-water equivalent corresponds to an energy amount for melting of $22 \mathrm{~W} \mathrm{~m}^{-2}$. Sensitivity analyses of Glaciar Yanamarey in the nearby Cordillera Blanca show that such a decrease of energy available for melting could be produced by a cloudiness increase of one-tenth, an air temperature decrease of more than $2^{\circ} \mathrm{C}$, a decrease in specific humidity of $1 \mathrm{~g} \mathrm{~kg}^{-1}$, or some combination of heat-budget processes. Such changes in the atmospheric environment would be required to stabilize the glacier at its recent volume. As another indication of the recent imbalance, the maximum volume flux is found about $100 \mathrm{~m}$ below the equilibrium-line altitude. Under continuation of recent climatic conditions, the glacier may disappear within a few decades. These inferences corroborate a recent assessment for the neighboring Cordillera Blanca.
\end{abstract}

\section{INTRODUCTION}

Mountain glaciers are sensitive indicators of climatic variations, and their role is generally recognized in international efforts to study global change. Sustained glaciological observation programs are, however, extremely rare in the tropical half of the Earth Haeberli and Hoelzle, 1993; Haeberli and others, 1993). With this background, the field observations maintained over extended periods in the Andes of northern Peru are particularly valuable (Ames and othes, 1988). In two recent papers (Hastenrath and Ames, 1995a,b) we analyzed the long-term glaciological record of Glaciar Yanamarey in Peru's Cordillera Blanca. Expanding on that effort, we now study a glacier in a neighboring mountain region of Peru. The observations on Glaciar Santa Rosa in the Cordillera Raura span 6 years and are evaluated here to assess the mode of operation of this tropical glacier in the context of the ongoing drastic ice recession.

\section{OBSERVATIONS}

The observational basis for this study consists of mapping of the ice-surface topography, net balance measurements at a network of stakes and determination of surface ice- flow velocity from repeated surveys of these stakes.

The surface topography of the glacier was mapped by terrestrial triangulation on 27 May 1980, at scale 1:5000 and with a contour spacing of $5 \mathrm{~m}$. The technique consisted of double theodolite triangulation from precision-surveyed control points on rock outside the glacier. These reference points are tied into the UTM coordinate system (Instituto Geográfico Militar, 1969, 1972). A simplified map at reduced scale is reproduced in Figure 1. Tolerance is estimated at better than $1 \mathrm{~m}$ in the vertical.

A map with date 16 October 1961 at the same scale and with the same contour spacing was produced by Geomecánica, Lima, by stereo-photogrammetric analysis of historical vertical air photographs (AF-60-17, VVAST-9, 1370 PMW-M7, frames 779 to 781) and using identified terrain-control points. Tolerance in vertical topography is estimated at a few meters.

Also available are the official 1:25000 topographic sheets (Instituto Geográfico Militar, 1969, 1972). Into these, the moraines identified in the 1961 air photographs were plotted and then transposed into the map (Fig. 1).

Net balance has been measured at a network of stakes from September 1977 through December 1983. Density measurements in representatively located pits permitted the conversion of readings of height changes into liquidwater equivalents. The stake network varied over the measurement period, with incomplete coverage in the 


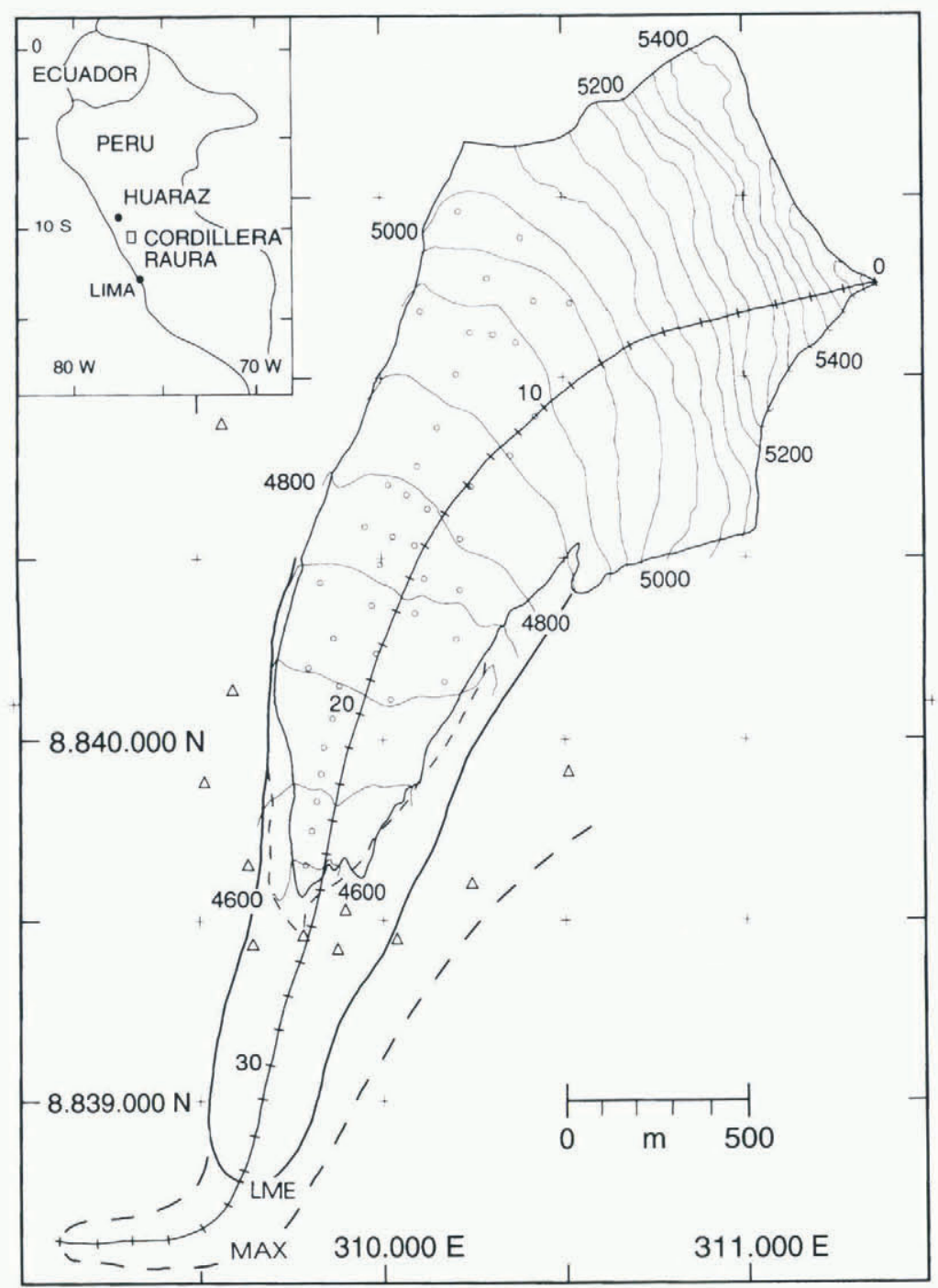

Fig. 1. Map of Glaciar Santa Rosa, 27 May 1980. Contour lines are at $50 \mathrm{~m}$ spacing, open triangles denote terrain-control points, and circles the location of net balance and motion stakes. Also entered is a central longitudinal line with tick marks at $100 \mathrm{~m}$ intervals (see Figs 2 and 3). Thin broken line indicates the 1961 boundary where different from 1980. An earlier maximum extent inferred from large moraines is indicated by heavy solid line (LME). A yet earlier moraine system is shown by heavy broken line and denoted as MAX. Scale 1:25000. Inset in upper left corner is location of Cordillera Raura within Peru.

upper reaches of the glacier during part of the period. No observations are available above $5200 \mathrm{~m}$. The map (Fig. 1) shows the distribution of stakes in 1982. Values are available as geometric height differences and as liquidwater equivalents.

Velocity measurements were obtained by repeated surveys of the stake positions. Observations were less numerous in some years than others, but a considerable sampling of the velocity field was obtained over the 6 year period. Displacements in the $x$ and $y$ coordinates were determined for all stakes, yielding the horizontal components of surface flow. In addition, for some of the stations the absolute elevation of a fixed mark on the stake (top of the stake) was also determined, thus yielding measurements of the vertical flow component.

\section{DATA ANALYSIS}

As a reference for the analyses a central longitudinal line was chosen with longitudinal distance counted down from the highest part of the glacier. This central reference line is shown in Figure 1 and is used as longitudinal coordinate in Figures 2 and 3. The glacier is divided into $100 \mathrm{~m}$ wide bands, bounded by lines perpendicular to the central longitudinal line.

In the construction of the representative vertical net balance profile, both the lack of readings in the upper reaches of the glacier and the variations from year to year have to be taken into account. For October 1977December 1983, the net balance was evaluated every $25 \mathrm{~m}$ from $4575 \mathrm{~m}$ upward. For each of these "standard" elevations, the liquid-water-equivalent net balance was averaged over all measured years, ideally 6 years, though fewer in the upper reaches of the glacier. Values above $5200 \mathrm{~m}$ are crude estimates from extrapolation. The resultant (liquid-water-equivalent) vertical net balance profile is displayed by the broken line in Figure 4. Multiplication by 1.12 yields the ice-volume-equivalent net balance plotted in Figure 4 as a solid line. 


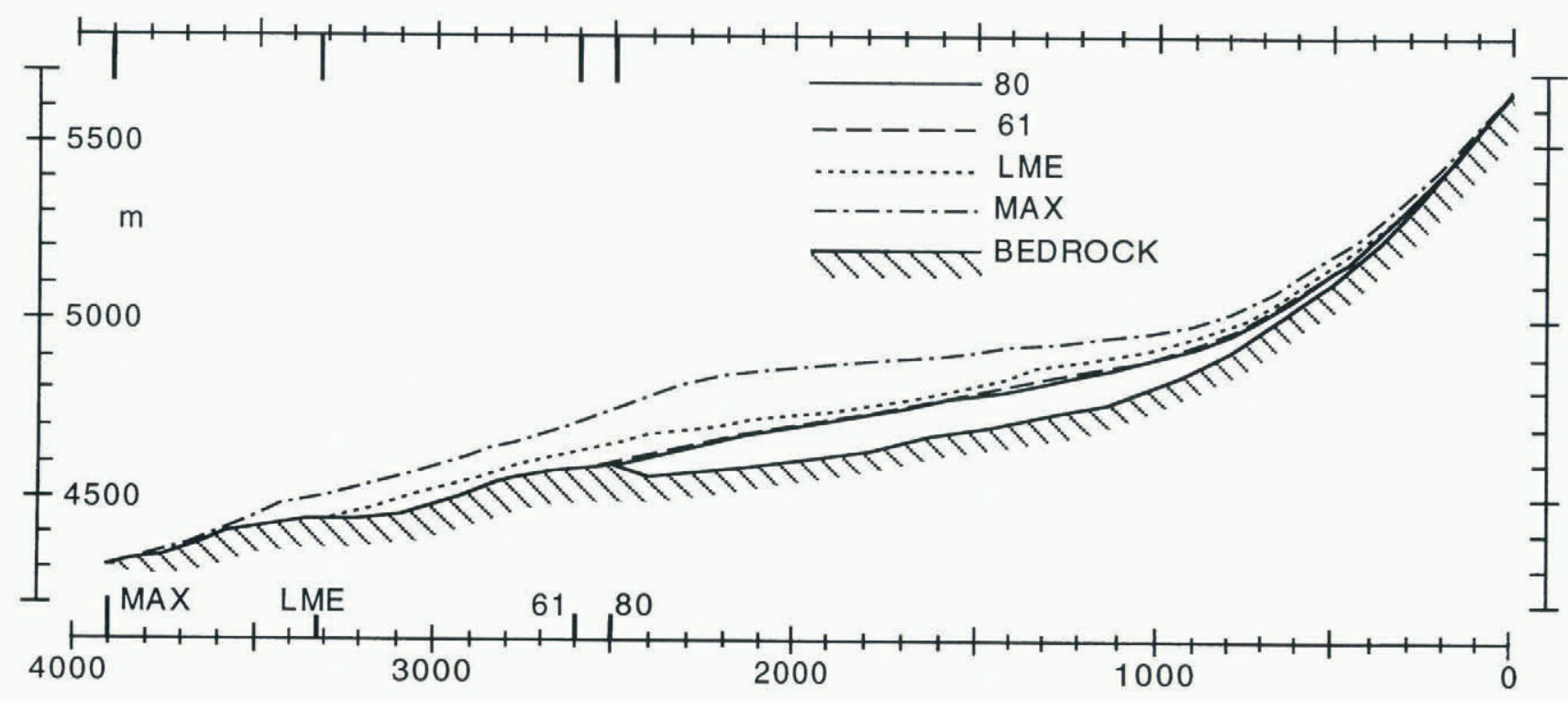

Fig. 2. Longitudinal-vertical cross-section along central line (Fig. 1). Cross-hatching denotes bedrock; dash-dotted, dotted, broken and solid lines denote the ice surface topography for MAX, LME, 1961 and 1980, respectively. Vertical tick marks show terminus positions for these dates. Scale 1:25000. No vertical exaggeration.

In an effort to cope with the uneven coverage of velocity measurements and interannual flow variability, it was essential to preserve the characteristic downstream variation of the flow while accounting for the variations in iceflow velocity from year to year. To that end, individual velocity measurements from nearby stakes were projected onto the central line (see Figs 1-3). For each year, values at $25 \mathrm{~m}$ intervals along this central line were obtained by linear interpolation between the measured points. For each year, these equidistant values were averaged over the 25 points from 1000 to $2500 \mathrm{~m}$ longitudinal distance, common to all years, and the values at $25 \mathrm{~m}$ spacing were expressed as departures from the $1000-2500 \mathrm{~m}$ mean. An overall average was then formed from the averages for the individual years. The departure values previously calculated for the individual years were added to this overall mean, so as to obtain six new longitudinal profiles of absolute velocity. These were then averaged to yield a representative longitudinal velocity profile.

For the $100 \mathrm{~m}$ wide bands defined by the equidistant points along the central longitudinal line (see Fig. 1), the values of (ice-volume-equivalent) net balance were compiled from the vertical net balance profile (Fig. 4). Net balance, surface lowering and velocity were all expressed as rates per year $\left(\mathrm{m} \mathrm{a}^{-1}\right)$.

\section{ICE DYNAMICS}

The following treatment of ice-flow dynamics is based on Hastenrath (1989) and on a series of earlier papers (Budd, 1969; Bhatt and others, 1981; Hastenrath and Kruss, 1982; Kruss, 1984; Hastenrath and Ames, 1995a). Directly pertinent here are only the relationships, described below in Equations (5) and (6), between longitudinal volume flux $\phi$, center-line surface velocity $V_{\mathrm{s}}$, ice thickness $Z$, surface width $W$, surface slope angle $\alpha$ and various parameters. These parameters are the constants $n$ and $k$ in a power flow law, stress-shape factor $s$, cross- section velocity ratio $C_{\mathrm{v}}$, and valley power $m$. Except for $k$ all are dimensionless. These are introduced in the following equations. Supported by experiences with similar glaciers (Kruss, 1984), only the deformational velocity is considered here and not the sliding velocity. Also, interest focuses on annual mean conditions rather than seasonal variations.

In a power flow law, the vertically averaged deformational velocity

$$
V_{\mathrm{i}}=k \tau_{\mathrm{b}}{ }^{n} Z
$$

where $\tau_{\mathrm{b}}$ is the center-line basal shear stress and $Z$ is the ice thickness. The stress-shape factor $s$ is introduced by (Nye 1965)

$$
\tau_{\mathrm{c}}=\operatorname{s\rho g} Z \sin \alpha
$$

where $\tau_{\mathrm{c}} \approx \tau_{\mathrm{b}}$ is the center-line downslope stress, $\rho$ is the ice density $\left(900 \mathrm{~kg} \mathrm{~m}^{-3}\right)$, and $g$ is the gravitational acceleration $\left(9.8 \mathrm{~m} \mathrm{~s}^{-2}\right)$.

The cross-sectional area is represented by:

$$
\Omega=\frac{m}{m+1} W Z \text {. }
$$

The cross-section velocity ratio

$$
C_{\mathrm{v}}=\bar{V} / V_{\mathrm{s}}
$$

where $\bar{V}$ is the cross-section mean velocity.

As explained in Kruss (1984) for a similar glacier, the constants used are $n=2, k=0.16$ bar $^{-2} \mathrm{a}^{1}, C_{\mathrm{v}}=0.7$, $s=0.9$ and $m=2$. The center-line surface velocity (Bhatt and others, 1981),

$$
V_{\mathrm{s}}=\left(\frac{n+2}{n+1}\right) k(\operatorname{s\rho g} \sin \alpha)^{n} Z^{n+1}
$$

or essentially a function of ice thickness $Z$ and surface slope angle $\alpha$. 

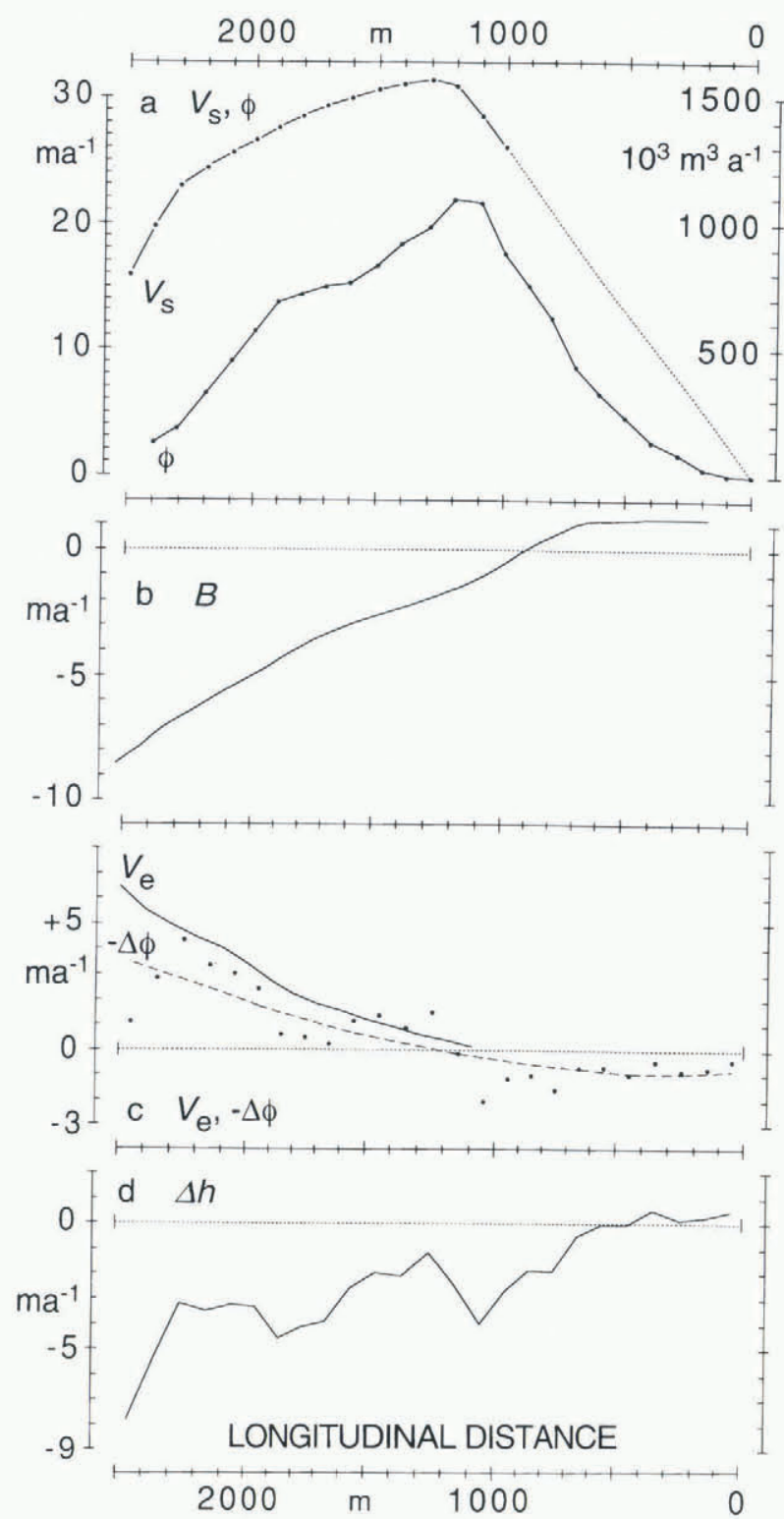

Fig. 3. Relation of net balance, surface lowering and iceflow velocity along longitudinal axis of glacier (Fig. 1). Horizontal scale in meters is counted from the highest point of the glacier down the longitudinal axis. Period is 197783 and horizontal scale 1:40000. (a) Center-line surface horizontal velocity $V_{\mathrm{s}}$ deduced from stake displacements (broken line) and extrapolated values at longitudinal distances less than $1000 \mathrm{~m}$ (dotted line) (lefthand scale), and longitudinal ice volume flux $\phi$ computed from Equation (6), (solid line, righthand scale); (b) icevolume-equivalent net balance $B$, as obtained from Figure 4 ; (c) emergence velocily $V_{\mathrm{e}}$ (solid line), and net volume inflow divided by area $-\Delta \phi$ (dots and broken line); (d) ice-thickness change $\Delta h$, calculated as $B-\Delta \phi$ from (b) and $(c)$.

Combining Equations (3) and (4) yields the volume flux, in $\mathrm{m}^{3} \mathrm{a}^{-1}$ (Hastenrath and Kruss, 1982),

$$
\phi=\left(\frac{m}{m+1}\right) C_{\mathrm{v}} W Z V_{\mathrm{s}} .
$$

This is essentially a function of center-line surface velocity $V_{\text {s, }}$, ice thickness $Z$ and surface width $W$.

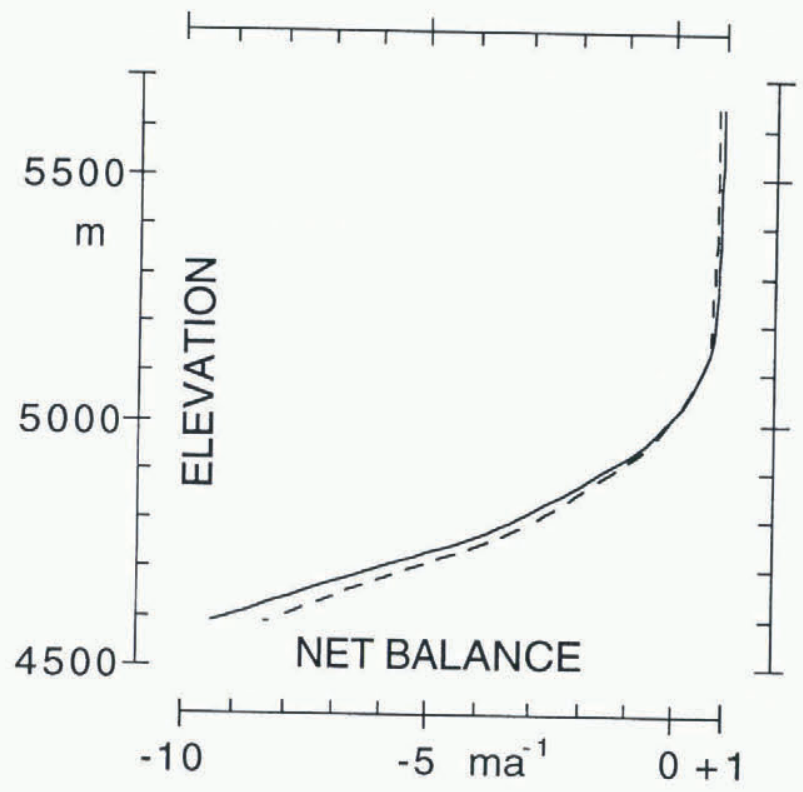

Fig. 4. Vertical net balance profile for period 1977-83; broken line denotes liquid-water equivalent, and solid line ice-volume equivalenl.

Equations (5) and (6) require information on the glacier morphology. The surface slope angle $\alpha$ along the central longitudinal line was read from maps of icesurface topography, and the surface width was evaluated at the boundaries between the $100 \mathrm{~m}$ wide bands. Given the measurements of surface flow velocity and the surface slope, the ice thickness $Z$ at the center line can be calculated from Equation (5), and the volume flux $\phi$ across the boundaries of the $100 \mathrm{~m}$ wide bands can then be computed from Equation (6).

As explained in section 2, in addition to the horizontal flow component some measurements of the vertical flow component are available. The procedure for determining this component is described in Paterson (1969, p. 65-68). Let $\Delta z$ and $\Delta s$ denote the displacements in the vertical and horizontal directions, respectively, along the central line (Figs 1, 2 and 3) during the time interval $\Delta t$, with $\tan \alpha$ the surface slope. Then the upward-directed "emergence velocity" is

$$
V_{\mathrm{e}}=\frac{1}{\Delta t}(\Delta s \tan \alpha-\Delta z) .
$$

This is related to the ice-thickness change $\Delta H$ and the (ice-volume-equivalent) net balance $B$ according to

$$
V_{\mathrm{e}}=\Delta H-B \text {. }
$$

\section{CHANGES IN ICE EXTENT AND VOLUME}

The broadly southward-facing Glaciar Santa Rosa extends from its steep upper reaches above $5600 \mathrm{~m}$ to a terminus around $4600 \mathrm{~m}$. At the last mapping in 1980, the glacier was about $2.5 \mathrm{~km}$ long with an area of $1.77 \mathrm{~km}^{2}$ (Table 1). An impression of the topography, from the mountain peaks behind to the valley below the glacier, is offered by Figure 2. In addition to the 1961 retreat status, two earlier and undated glacier stages can be identified as 
Table 1. Length, terminus elevation, area and total volume of Glaciar Santa Rosa al maximum extent (MAX), last maximum extent (LME) and on 16 October 1961 and 27 May 1980

\begin{tabular}{lrrrr}
\hline & MAX & LME & 1961 & 1980 \\
\hline Length $(\mathrm{m})$ & 3900 & 3320 & 2600 & 2500 \\
Terminus $(\mathrm{m})$ & 4308 & 4435 & 4570 & 4580 \\
Area $\left(10^{3} \mathrm{~m}^{2}\right)$ & 2679 & 2186 & 1826 & 1774 \\
Volume $\left(10^{6} \mathrm{~m}^{3}\right)$ & 331 & 132 & 78 & 73 \\
\hline
\end{tabular}

explained in section 2, namely a "maximum extent" here denoted as MAX, and a "last maximum extent" referred to as LME (see Figs 1 and 2; Table 1).

In addition to the maps of high precision for 1980 and 1961 , it proved possible to estimate from the mapping of the moraines of stages MAX and LME not only the lateral ice extent but also the ice-surface topography. For longitudinal distances beyond $1300 \mathrm{~m}$ for LME, and beyond $2200 \mathrm{~m}$ for MAX, this was taken as equal to the elevation of the crest of the lateral moraine, read at $100 \mathrm{~m}$ intervals. Assuming that conditions remained unchanged at the upper ice margin, values for the upper part of the glacier were obtained by linear interpolation betweeen, respectively, 0 and $1300 \mathrm{~m}$, and 0 and $2200 \mathrm{~m}$ longitudinal distance. Uncertainties in ice-surface topography are estimated as a few meters for MAX up to $2200 \mathrm{~m}$ and for LME up to $1300 \mathrm{~m}$ longitudinal distance, with tolerances substantially larger above those limits.

Table 1 summarizes the changing ice extent and volume for the four mapping states. From lengths of $3900 \mathrm{~m}$ at MAX and $3320 \mathrm{~m}$ at LME, the glacier retreated to $2600 \mathrm{~m}$ by 1961 , with a further shortening to $2500 \mathrm{~m}$ by 1980 . Accompanying the retreat of the glacier tongue are a rise of the terminus and massive shrinkages in area and volume from MAX to LME and 1961, followed by more modest changes over the presumably much shorter interval 196180. The calculation of the absolute ice volume in 1980 is described in section 6. In Table 1, uncertainties are estimated at a few meters for length and terminus elevation, about $10^{5} \mathrm{~m}^{2}$ for area and about $20 \times 10^{6} \mathrm{~m}^{3}$ for the 1980, 1961 and LME volumes, with tolerances as large as $60 \times 10^{6} \mathrm{~m}^{3}$ for MAX.

The reconstructed ice-surface topography along the central longitudinal line for MAX, LME, 1961 and 1980 is shown in Figure 2, along with the bedrock topography. For the longitudinal distances up to $2500 \mathrm{~m}$ the ice thickness and thus the bedrock topography were calculated from Equation (5) using as input the 6 year mean center-line surface velocity (Fig. 3a) and the 1980 ice-surface topography (Fig. 1). Tolerances in the calculated ice thickness $Z$ are estimated as less than $10 \mathrm{~m}$.

\section{ICE FLOW AND MASS CONTINUITY}

The average functioning of Glaciar Santa Rosa is summarized in Figure 3. The center-line surface velocity (Fig. 3a) peaks around $1300 \mathrm{~m}$ longitudinal distance with more than $31 \mathrm{ma}^{-1}$. This is established by the measurements between 1000 and $2500 \mathrm{~m}$ longitudinal distance as discussed in sections 2 and 3 , while values upward of $1000 \mathrm{~m}$ were obtained by extrapolation to zero velocity at the upper boundary of the glacier. The surface velocities at equidistant points along the central line in Figure 3a, along with readings of surface slope, served as input to Equation (5) to obtain ice-thickness estimates. These are combined with the 1980 surface topography in the longitudinal profile in Figure 2 to construct the bedrock topography. Figure 2 shows a maximum ice thickness of about $100 \mathrm{~m}$ at longitudinal distances of $1700-2000 \mathrm{~m}$.

Values of ice thickness $Z$, having thus been created, were used together with the measured center-line surface velocity $V_{\mathrm{s}}$ and width $W$ to calculate the volume flux $\phi$ from Equation (6). The resultant longitudinal profile in Figure 2 exhibits a maximum of $1090 \times 10^{3} \mathrm{~m}^{3} \mathrm{a}^{-1}$ at a longitudinal distance of $1200 \mathrm{~m}$. Differentiating with respect to longitudinal distance, or forming the difference of volume flux across successive boundaries, yields the net outflow or inflow to each $100 \mathrm{~m}$ wide band. For mass continuity, this volume-flux divergence would have to be compensated by the net balance minus the change in surface elevation, integrated over the respective band.

The net balance for these bands, obtained from the stake network, as described in section 3, is plotted in Figures $3 \mathrm{~b}$ and 4 . Net balance is positive only above $5000 \mathrm{~m}$, changing to progressively larger negative values in the lower glacier, so that values around $-9 \mathrm{ma}^{-1}$ are found near the terminus (Fig. 3b).

The convergence of volume flux calculated from Figure $3 \mathrm{a}$ by spatial differentiation, and divided by area, $-\Delta \phi$, is plotted in Figure 3c. The scatter of points is related to small irregularities in the longitudinal profile of $\phi$ shown in Figure $3 \mathrm{a}$. The smooth broken line drawn through these points illustrates divergence of volume flux upward from the volume-flux maximum near $1200 \mathrm{~m}$ longitudinal distance (Fig. 3a), giving way to convergence farther down the glacier. As described in section 4 , $-\Delta \phi$ should be compared to the emergence velocity $V_{\mathrm{e}}$, likewise plotted in Figure 3c. Both curves show the characteristic change towards larger positive values down-glacier and overall similar magnitude. However, $V_{\mathrm{e}}$ is in general somewhat larger, presumably because it represents conditions at the center line rather than area averages over bands.

The rate of thickness change by $100 \mathrm{~m}$ bands, obtained from the net balance (Fig. 3b) and the volume-flux convergence (Fig. 3c), is plotted in Figure $3 d$. Irregularities in this curve reflect those of $-\Delta \phi$ (Fig. $3 c)$ and thus stem from details in the longitudinal profile of the volume flux $\phi$ in Figure 3a. Overall, however, Figure $3 \mathrm{~d}$ shows the realistic pattern of ice-thinning increasing from near zero at $700 \mathrm{~m}$ longitudinal distance to values of more than $5 \mathrm{~m} \mathrm{a}^{-1}$ near the terminus. For the glacier as a whole the rate of volume change is -3163 $\times 10^{3} \mathrm{~m}^{3} \mathrm{a}^{-1}$, which with a 1980 area of $1774 \times 10^{3} \mathrm{~m}^{2}$ amounts to a glacier-average rate of ice-thickness change of $-1.78 \mathrm{~m} \mathrm{a}^{-1}$.

Figure 3 synthesizes the general mode of operation of Glaciar Santa Rosa. From the nature of the observation set it is difficult to estimate the uncertainties in the various elements. The present appraisal follows the considerations 
in a study of Glaciar Yanamarey (Hastenrath and Ames, 1995a). As representative of the multi-year average conditions, surface ice-flow velocity $V_{\mathrm{s}}$ may be captured at better than $10 \%$. Because of the cubic relationship in Equation (5), ice thickness is formally constrained more narrowly, but as a model result no error margin much better than $10 \%$ should be claimed. From such tolerances for $V_{\mathrm{s}}$ and $Z$, the uncertainty in the volume flux $\phi$ comes closer to $20 \%$. Again, as representative of multi-annual mean conditions, tolerances of about $10 \%$ may be assigned to net balance $B$. The surface-lowering rate $-\Delta h$ and the emergence velocity $V_{\mathrm{e}}$ may be even less well determined. Estimates of all elements are particularly uncertain for the poorly observed upper reaches of the glacier.

Regarding the age of the ice within Glaciar Santa Rosa, an average residence time can be calculated by dividing the volume of the upper glacier by the outflow rate. To that end, an estimate of the absolute ice thickness and volume in 1980 was derived as follows. Assuming parabolic shape, the center-line depth computed from Equation (6) and plotted in Figure 2, along with the observed width, define the bedrock topography along the lines placed at $50 \mathrm{~m}$ intervals perpendicular to the central line. These values were digitized at $100 \mathrm{~m}$ spacing, and interpolated onto a rectangular grid with $2 \mathrm{~m}$ cell size. Ice thickness and volume for the $100 \mathrm{~m}$ wide bands were then evaluated digitally. The 1980 volumes for the domains upward and downward from $1200 \mathrm{~m}$ longitudinal distance and the glacier as a whole were thus estimated as 35,38 and $73 \times 10^{6} \mathrm{~m}^{3}$, respectively, As shown by Figure $3 \mathrm{a}$, the maximum volume flux is $1090 \times 10^{3} \mathrm{~m}^{3} \mathrm{a}^{-1}$ at $1200 \mathrm{~m}$ longitudinal distance. Dividing the volume above the $1200 \mathrm{~m}$ cross-section by this "flushing rate" yields an "average residence time" of ice in the upper glacier of about 32 years. By way of comparison, an average residence time of about 42 years was estimated for Glaciar Yanamarey in Peru's Cordillera Blanca (Hastenrath and Ames, 1995a), where ice flow is substantially slower.

\section{GLIMATIC FORCING AND WATER BUDGET}

Hydrological and climatic implications of the results of section 6 are considered in this section.

Regarding the liquid-water budget of the glacier as a whole, we can write for annual mean conditions, and neglecting the mass loss by evaporation and direct sublimation,

$$
A P-A B^{*}=R
$$

where $A$ in $\mathrm{m}^{2}$ is the area of the glacier, $P$ and $B^{*}$ in $\mathrm{m} \mathrm{a}^{-1}$ are (liquid-water-equivalent) precipitation and net balance, respectively, and $R$ in $\mathrm{m}^{3} \mathrm{a}^{-1}$ is the water runoff from the glacier. The analysis in section 6 leads to estimates of the rate of liquid-water-equivalent volume change of $3542 \times 10^{3} \mathrm{~m}^{3} \mathrm{a}^{-1}$, and of the glacier-average rate of ice-thickness change of $-2.0 \mathrm{~m} \mathrm{a}^{-1}$. Precipitation was measured during $1970-77$ in a site at $4900 \mathrm{~m}$ about $5 \mathrm{~km}$ from the glacier. The average annual precipitation over these 8 years was $1200 \mathrm{~mm}$, all of which fell in solid form. Together with the above estimate of ice-thickness change, this yields an annual mean water discharge from the glacier of $180 \mathrm{ls}^{-1}$, and of this total about $1101 \mathrm{~s}^{-1}$ stems from the mass loss of the glacier. This means that more than half of the water discharge from the glacier is not at present renewed by precipitation but is supplied by the progressive thinning of the glacier.

The rate of surface-lowering indicated in Figure 3d corresponds to a glacier-average liquid-water-equivalent deficit of $2.0 \mathrm{~m} \mathrm{a}^{-1}$. To stabilize the glacier at its present volume would require a substantial shift of the vertical net balance profile (Fig. 4) along its vertical and/or horizontal axes. Complications due to the changing iceflow pattern and glacier morphology are disregarded here. Instead, we estimate in the following the typical magnitudes of changes in the climatic conditions that would account for the observed glacier-average liquidwater-equivalent net balance deficit of $2.0 \mathrm{~m} \mathrm{a}^{-1}$.

Least plausible would be a change of solid precipitation by this large amount, which exceeds the actual annual precipitation. More pertinent are processes affecting the glacier energy budget. With a latent heat of melting $L_{\mathrm{m}}=33 \times 10^{4} \mathrm{~g} \mathrm{~kg}^{-1}$, the liquid-water-equivalent $2.0 \mathrm{~m} \mathrm{a}^{-1}$ corresponds to $22 \mathrm{~W} \mathrm{~m}^{-2}$. In a recent study for Glaciar Yanamarey in the nearby Cordillera Blanca Hastenrath and Ames, 1995a,b), we found corresponding imbalances of $1.5 \mathrm{~m} \mathrm{a}^{-1}$ and $16 \mathrm{~W} \mathrm{~m}^{-2}$, and calculated the heat-budget forcings that could produce such a difference in energy supply. Based on these results, a decrease of energy available for melting of $22 \mathrm{~W} \mathrm{~m}^{-2}$ could be accounted for by a cloudiness increase of one-tenth, an air-temperature decrease of more than $2^{\circ} \mathrm{C}$, a decrease in specific humidity of $1 \mathrm{~g} \mathrm{~kg}^{-1}$, or some combination of these factors.

As a further indication of imbalance, note that for an equilibrium glacier the maximum volume flux coincides with the equilibrium-line altitude (ELA). By contrast, at Glaciar Santa Rosa in its recent state the maximum volume flux is nearly $4900 \mathrm{~m}$ (Figs 2 and 3a), or well below the ELA at $5000 \mathrm{~m}$ (Fig. 4). We found a similar discrepancy of about $100 \mathrm{~m}$ in our recent study of Glaciar Yanamarey (Hastenrath and Ames, 1995a).

Parallel to our study for Glaciar Yanamarey (Hastenrath and Ames, 1995a), inference is also desired on how long the glacier could survive under continuation of the recent climatic conditions. The ice volume above $1200 \mathrm{~m}$ longitudinal distance was estimated at $35 \times$ $10^{6} \mathrm{~m}^{3}$, and net balance in the upper glacier adds up to a loss of $332 \times 10^{3} \mathrm{~m}^{3} \mathrm{a}^{-1}$. The outflow would decrease from its recent value (Fig. $3 \mathrm{a}$ ) to zero when the glacier disappears, so that the arithmetic mean of $545 \times$ $10^{3} \mathrm{~m}^{3} \mathrm{a}^{-1}$ may be adopted as representative. Thus net balance and outflow would deplete the volume of the upper glacier within about 40 years. The volume of the lower glacier, below $1200 \mathrm{~m}$ longitudinal distance, was estimated at $38 \times 10^{6} \mathrm{~m}^{3}$. Net balance would with the present area add up to a loss of $2955 \times 10^{3} \mathrm{~m}^{3} \mathrm{a}^{-1}$. Considering the progressive shrinkage in area a value of about $15 \times 10^{6} \mathrm{~m}^{3} \mathrm{a}^{-1}$ may be taken as representative. Combining the estimates from net balance and influx, the recent volume of the lower glacier could be consumed within about 41 years. Shortcomings of these calculations have been pointed out in an earlier paper (Hastenrath and Ames, 1995a): the estimates of the recent volume are 
crude: ice near the center line is thicker and may persist longer; surface lowering results in more negative net balance even without changes of climate; and changing flow dynamics complicate the development. For the upper glacier, the reduced outflow rate is counteracted by the more negative net balance. With these reservations, we estimate that under the recent climatic conditions Glaciar Santa Rosa may last another 40 years. This value is similar to the estimate obtained for Glaciar Yanamarey (Hastenrath and Ames, 1995a).

\section{SUMMARY AND CONCLUSIONS}

The present investigation into the mode of operation of Glaciar Santa Rosa in the Cordillera Raura of Peru expands on our recent study of Glaciar Yanamarey in the neighboring Cordillera Blanca (Hastenrath and Ames, $1995 \mathrm{a}, \mathrm{b})$. A rare accomplishment for the tropical half of the Earth, multi-year measurement programs have been maintained on these glaciers in the Peruvian Andes, inviting an evaluation for their climatic-information content. It proved possible to reconstruct the ice extent and volume for two undated moraine stages, MAX and LME, and 1961 and 1980, the dates of the most recent topographic map of Glaciar Santa Rosa. These revealed massive shrinkage from the early moraine stages to 1961 and more modest changes over the next two decades. For the period 1977-83 of the montioring program, the measurements of ice-surface flow velocity and net balance were evaluated in the framework of an ice-dynamics model of flow along the central line of the glacier.

The vertical net balance profile of Glaciar Santa Rosa is characterized by positive values above about $5000 \mathrm{~m}$, and negative values increasing to around $-9 \mathrm{ma}^{-1}$ near the terminus. Surface lowering is estimated at about $2 \mathrm{~m} \mathrm{a}^{-1}$ for the glacier as a whole, with values nearly twice as large near the terminus. The volume flux peaks with $1090 \times 10^{3} \mathrm{~m}^{3} \mathrm{a}^{-1}$ near a longitudinal distance of $1200 \mathrm{~m}$ from the upper edge, where the surface ice-flow velocity also reaches its maximum of $31 \mathrm{~m} \mathrm{a}^{-1}$. The ice thickness increases from around $30 \mathrm{~m}$ in the upper to more than $90 \mathrm{~m}$ in the lower glacier.

Based on this appraisal of the functioning of the glacier, some inferences can be offered on the water budget and climatic forcing. The annual mean water discharge from the glacier is about $200 \mathrm{ls}^{-1}$, and more than half of this stems from the thinning of the ice and is not replaced by solid precipitation. For Glaciar Santa Rosa to stabilize at its recent volume, the glacier-average (liquid-water-equivalent) net balance would have to be $2 \mathrm{ma}^{-1}$ larger. This corresponds to a reduction of the heat available for melting by about $22 \mathrm{~W} \mathrm{~m}^{-2}$. A decrease of the energy supply for melting by this amount could be accounted for by a cloudiness increase of one-tenth, an air temperature decrease of more than $2^{\circ} \mathrm{C}$, a decrease in specific humidity of $1 \mathrm{~g} \mathrm{~kg}^{-1}$, or some combination of these and other factors. As a further measure of the recent imbalance, the maximum volume flux is found some $100 \mathrm{~m}$ below the ELA. Under the recent climatic conditions, the glacier may survive another 40 years. Overall, this investigation of Glaciar Santa Rosa in the Cordillera Raura corroborates our inferences for another glacier in a neighboring region of the North Peruvian Andes.

\section{ACKNOWLEDGEMENTS}

This study was supported by U.S. National Science Foundation grant EAR-9217211. At the University of Wisconsin, L. Greischar and D. Polzin assisted with the data processing and graphics.

\section{REFERENCES}

Ames, A. and 7 others. 1988. Inventario de glaciares del Peri. Huaraz, Peru, Unidad de Glaciología e Hidrología.

Bhatt, N., S. Hastenrath and P.D. Kruss. 1981. Ice thickness determination at Lewis Glacier, Mount Kenya: seismology, gravimetry, dynamics. Z. Gletscherkd. Glazialgeol., 16 2), 213-228.

Budd, W. 1969. The dynamics of ice masses. ANARE Sci. Rep., Sec. A, Glaciol. 108.

Haeberli, W. and M. Hoelzle, comps. 1993. Fluctuations of glaciers 1985-1990 (Vol. V1). A contribution to the Global Environmental Monitoring System (GEMS) and the International Hydrological Programme. Wallingford, Oxfordshire, International Association of Hydrological Sciences, IAHS Press; Nairobi, United Nations Environment Programme; Paris, UNESCO.

Hacberli, W., E. Herren and M. Hoelzle, eds. 1993. Glacier Mass Balance Bulletin, Bulletin No. 2 (1990-1991). Paris, IAHS (ICSI), UNEP, UNESCO.

Hastenrath, S. 1989. Ice flow and mass changes of Lewis Glacier, Mount Kenya, East Africa: observations $1974-86$, modelling, and predictions to the year 2000 A.D. F. Glaciol., 35 (121), 325-332.

Hastenrath, S. and A. Ames. 1995a. Diagnosing the imbalance of Yanamarey Glacier in the Cordillera Blanca of Peru. f. Geophys. Res., 100 D3), 5105-5112.

Hastenrath, S. and A. Ames. 1995b. Recession of Yanamarey Glacier in Cordillera Blanca, Peru, during the 20th century. F. Glaciol., 41 (137), $191-196$.

Hastenrath, S. and P. Kruss. 1982. On the secular variation of ice flow velocity at Lewis Glacier, Mount Kenya, Kenya. J. Glaciol., 28(99), 333339.

Instituto Geográfico Militar, Peru. 1969. Uchuc Chacu. Lima, Instituto Geográfico Militar. Carta Nacional hojo 21-j-I-NO, Scale $1: 25,000$.

Instituto Geográfico Militar, Peru. 1972. Nevado Raura. Lima, Instituto Geográfico Militar. Carta Nacional hojo 21-j-II-SO, Scale 1:25,000.)

Kruss, P. 1984. Terminus response of Lewis Glacier, Mount Kenya, Kenya to sinusoidal net-balance forcing. f. Glaciol., 30 105), $212-217$.

Nye, J.F. 1965. The flow of a glacier in a channel of rectangular, elliptic or parabolic cross-section. J. Glaciol., 5(41), 661-690.

Paterson, W.S.B. 1969. The physics of glaciers. Oxford, etc., Pergamon Press. 